\title{
Effects of 8 weeks water cure with aquatic devices on static balance and velocity of gait among elderly men
}

\author{
Y. Khanjari (M.A) -E. A. Ameri (Ph.D) \\ University of Tehran, University of Tehran \\ Corresponding Author: \\ ykhanjari@gmail.com
}

Keywords: water cure, static balance, velocity of gait, elderly men.

\begin{abstract}
Background: Aging is a stage of life that increases the risk of physical diseases, some of which are chronic and can affect different dimensions of life's quality. Hydrotherapy is used to treat rheumatic, orthopedic and neurological disorders. It has been the subject of investigations regarding balance and gating recovery in elderly people.

Objective: To evaluate the effect 8 weeks water cure program with aquatic devices on static balance and velocity of gait in elderly men.

Methods: Fifteen old men were chosen purposely by age mean and Std 58 \pm 6.5 , length $167.12 \pm 7.35$ $\mathrm{cm}$, weight 75.64 \pm 7.64 . We used the Sharpened Romberg test (static balance with eyes open and close) and Timed Up \& Go(for evaluating velocity of gait). we used a selected program in water with aquatic devices in 8 weeks. Water exercise session included of three parts warm up, main part of exercise, and cool down. we analyzed the achieved data by a correlated t-test at a meaningful level $(\mathrm{p} \leq 0.05)$.

Results: Among the post-test and pre-test Romberg test $(\mathrm{p} \leq 013)$ and the velocity of gait $(\mathrm{p} \leq 005)$ were recovered meaningfully after the program.

Conclusions: The results showed that participating in an exercise in water program with aquatic devices on a regular basis can be considered as an effective and reliable method to increase balance, and it can promote quality and velocity of gait among these aged men.
\end{abstract}

\section{INTRODUCTION}

According to the current statistics, Iran's population will tend towards ageing in the years to come. Therefore, the period of aging itself needs to be investigated as a stage in one's life( Khanjari et. al 2015). Nowadays, falls are one of the largest public health problems among elderly people due to the high morbidity, mortality and costs for the family and society (Stevens \& Olson 2000). The main risk factors for falls in thispopulation are related to functional limitations, history of falls, increasing age (Stevens \&Olson 2000;Newton1995), muscle weakness, use of psychotropic drugs, environmental risks (Stevens \& Olson 2000 ;Newton1995;Gregg et al 2000), and visual deficits (Perracini \& Ramos 2002). Researchers have reported that elderly womenhave a higher propensity for falls because of less lean body mass and muscle strength, a higher prevalence ofchronicdegenerative diseases and exposure to domestic activities.

Every year in the United States (Fuller 2000), 30\% of non-institutionalized elderly people suffer falls.Approximately $5 \%$ of these cause fractures, especially in the hips (Perracini\&Ramos2002). In the United States, theannual cost of treating hip fractures among elderly people caused by falls is 10 billion dollars (Carter et al 2001).

Thus, it is recognized in the literature that physical activity practiced throughout life can diminish bone andmuscle loss, and reduce the risk of fractures by up to $60 \%$ (Stevens\&Olson2000; Gregg et al 2000), In addition,physical activity promotes increased muscle strength, aerobic conditioning, flexibility and balance, and reduces therisk of falls and improves quality of life (Barnett et al 2003; Gregg et al 2000).

Since long ago, hydrotherapy has been used as a resource for treating rheumatic, orthopedic and neurologicaldiseases; however, it has only recently become the target of scientific studies. The 
physical proprieties of water,together with the exercises, can fulfill most of the physical objectives that are proposed in a rehabilitation program.

The aquatic environment is considered safe and efficient for the rehabilitation of elderly people, because water actssimultaneously on musculoskeletal disorders and balance improvements (Booth 2004;Caromano\&Candeloro2007). The multiplicity of symptoms such as pain, muscle weakness, balance deficits, obesity, arthritic diseases and gaitdisorders, among others, make it difficult for elderly people to perform exercises on the ground. The situation isdifferent with exercises in an aquatic environment, where there is a reduction in joint overload and less risk of fallsand lesions. In addition, floating allows individuals to perform exercises and movements that cannot be done on the ground (Geigle et al 1997;Booth2004;Simmons\&Hansen1996). Khanjari et. $\mathrm{al}(2015)$ in analyzing the effect of a period of aquatic therapy exercise on the quality of life and depression in aged males suffering from chronic physical pains showed that exercise in water created a meaningful promotion in pain scale, life quality and depression(Khanjari et. al 2015). Khanjari et. al(2015) in another study showed that participating in an exercise in water program on a regular basis can be considered as an effective and reliable method to decrease pain, promote the operation of knee and the old men life's quality(Khanjari et. al 2015).

Although few studies have reported the effects of hydrotherapy on balance and the reduction of falls, all of themhave shown benefits, for example, of reduced postural oscillations (Lord et al 1993), increased functional reach(Simmons\&Hansen1996) and greater independence in activities of daily living (ADLs)(Rissel1987). Given therelevance of this subject, the objective of the present study was to evaluate the effects of hydrotherapy in static anddynamic balance among elderly men.

\section{MATERIALS AND METHODS}

The nature of this study is applied and semi-experimental in pre-test and post-test research. The study population consisted of all the elderly male that referred to the Niyayesh Health Center in Shiraz. At first the form of collecting data by which the age, weight, height, physical activity, history of illness or medication was determined by holding interviews and controlled the individuals health or illness conditions and injuries.

The materials consisted of the following: a questionnaire for interview, the Sharpened Romberg test(Paula et a12000), the Timed Up \& Go test (Podsiadlo\&Richardson1991), a chronometer (Sport Timer), two chairs of $45 \mathrm{~cm}$ inheight (one of them with arms), swimming pool measuring 6.5 by 13.5 meters, with a sloping bottom with the depth going from .9 to 1.7 meters, and with a mean temperature $33 \mathrm{C}$.

\section{The Water Exercise Protocol by means of aquatic devices}

The 8-week training consisted of three weekly sessions, each lasting 50 to 70 minutes progressively and increasingly with 40 to $60 \%$ of the maximum heart rate reserve. Water exercise session included of three parts warm up, main part of exercise, and cool down. Fifteen minutes of warm-up activities included walking in the water and doing stretching exercises. The main part of exercise included simple activities in the lower organs for 15 minutes and using water treatment devices in the water, including cycling, skiing and step for strengthening the muscle of the subjects. It should be noted that all the devices are embedded into the water and the subjects did exercise training on each devices for 4 to 5 minutes and then rest for Tow minutes. Subjects were asked to do the exercises to the severity of the pain threshold. Finally at the end of each session subjects did some stretching and flexibility activities to come back the initial status for 5 minutes. It would be noted that all participants had signed the consent for performing this study. After the initial evaluation, subjects carried out a 8-week water exercise under the supervision of a hydrotherapy instructor, at the end the final evaluation was done. 


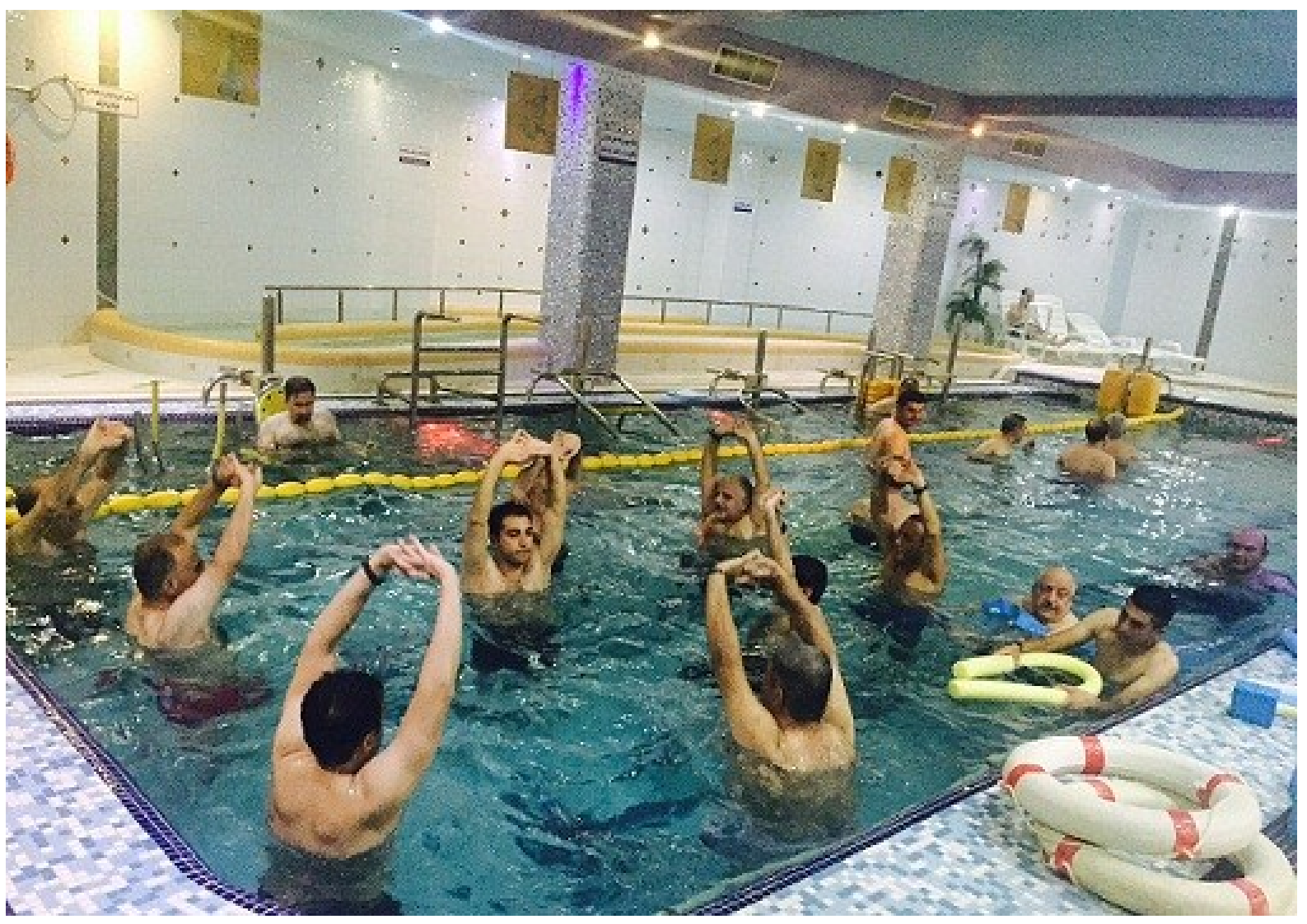

\section{RESULTS}

The average and standard deviation, demographic and physical characteristics of people in research is shown in table 1.

Table 1. Mean and standard deviation of the physical qualities of the subjects

\begin{tabular}{|c|c|}
\hline Physical Qualities & Standard Deviation \pm Mean \\
\hline Age $($ year $)$ & $58 \pm 6.5$ \\
\hline Length $($ centimeter $)$ & $167.12 \pm 7.35$ \\
\hline Weight $(\mathrm{km})$ & $75.64 \pm 7.64$ \\
\hline
\end{tabular}

According to the obtained results, the hydrotherapy program promoted significant in the elderly men balance, as observed by means of the Sharpened Romberg test (static balance with eyes open $(p \leq 0.001)$ and static balance with eyes open close $(p \leq 0.002))$. The increase occurred after the 8 weeks (Table 1).

Likewise, the Timed Up \& Go test showed that there was a significant decrease in the elderly men times taken to perform the tests after the hydrotherapy program, after the 8 weeks $(p \leq 0.001)$ (Table 1).

No differences were noted between control group in static balance with eyes open and close and the Timed Up \& Go test.

Table 2.( $\mathrm{M} \pm \mathrm{SD})$ of the differences in elderly men before and after the program of hydrotherapy for static/dynamic balance obtained by means of the Student $t$ test for paired data. 


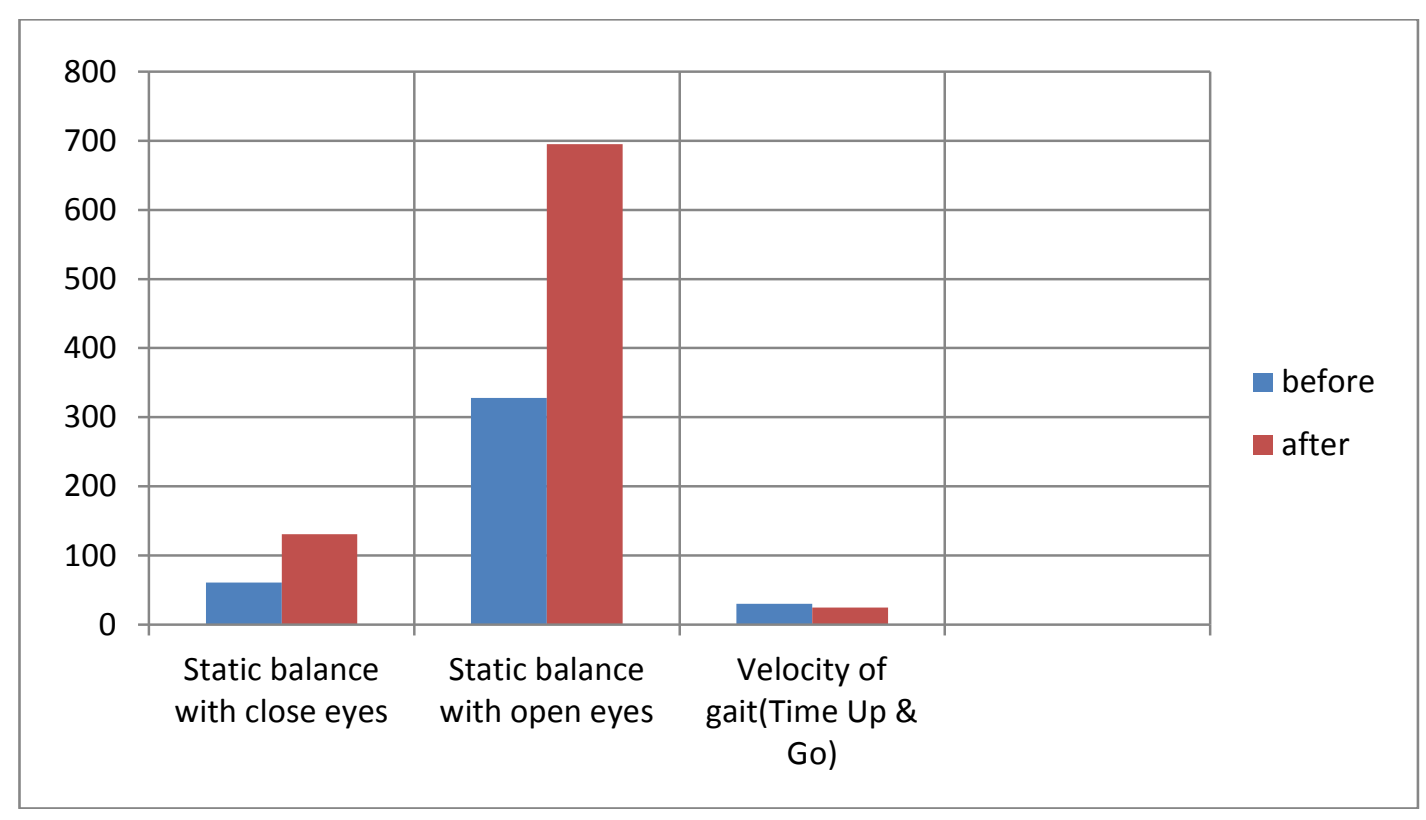

\begin{tabular}{|c|c|c|c|c|c|}
\hline \multirow{2}{*}{ variables } & \multicolumn{2}{|c|}{ Standard Deviation \pm Mean } & \multicolumn{2}{|c|}{ Correlated t-test } \\
\cline { 2 - 6 } & Before & After & significance & $\begin{array}{c}\mathbf{t}- \\
\text { value }\end{array}$ & df \\
\hline Static balance with close eyes & $63.35 \pm 61.42$ & $72.43 \pm 131.25$ & $0 / 013$ & $-2 / 29$ & 14 \\
\hline Static balance with open eyes & $156.13 \pm 328.52$ & $422.11 \pm 695.422$ & $0 / 006$ & $-2 / 59$ & 14 \\
\hline Velocity of gait(Time Up \& Go) & $1.39 \pm 11.28$ & $1.16 \pm 8.11$ & $0 / 005$ & $-2 / 94$ & 14 \\
\hline
\end{tabular}

\section{DISCUSSION AND CONCLUSION}

According to the obtained results, balance and velocity of gait increased significantly after conducting the cure water program by means of aquatic devices, according to Sharpened Romberg test (static balance with eyes open and close) and the Timed Up \& Go test. This was similar to the results obtained by many other authors (Booth2004; Simmons \& Hansen1996; Lord et al 1993; Douris et al 2003;Devereux et al 2005; Resende et al 2008) in which the application of a water cure program increased balance among elderly people. However, the functional tests and treatment programs used in these studies were different, making it difficult to make quantitative comparisons.

Studies that have found increased balance and velocity of gait after hydrotherapy programs have also suggested that there is a reduction in the risk of falls, since balance has a direct relation with these risks (Booth2004;Simmons\&Hansen1996; Douris et al 2003). These authors did not use a model with scoring that predicted the risk of falls, but was evaluated indirectly. That is, they classified the elderly people as having a low, medium or high risk of falls according to the score obtained in the balance tests. Thus, it can be suggested that subsequent studies should use scales for scoring the risk of falls, in order to directly obtain results.

Other authors are unanimous regarding the indication of aquatic exercises for individuals with fear of falling who are at risk of falls (Booth2004;Simmons \& Hansen1996; Douris et al 2003; Devereux et al 2005; Resende et al 2008). Water is viscous: it decelerates movement and retards falls, which prolongs the time available for regaining posture when the body gets out of balance. Floating acts as a support, which increases individuals confidence and reduces the fear of falling. In this way, individuals can be challenged beyond their limits of stability without being afraid of the consequences of falls that would occur on the ground (Geigle et al 1997; Salzman1998).

This water cure program was effective in static balance and velocity of fait and increased significantly among elderly men. These can vary from small injuries, mobility restrictions, limitations in ADLs and loss of functional independence, up to social isolation, can create a vicious circle of voluntary restriction of activities and, thus severely compromises the quality of life (Perracini\& Ramos2002; Fabricio et al 2004) Khanjari et. al(2015) in analyzing the effect of a 
period of aquatic therapy exercise on the quality of life and depression in aged males suffering from chronic physical pains showed that exercise in water created a meaningful promotion in pain scale, life quality and depression(Khanjari et. al 2015). Khanjari et. al(2015) in another study showed that participating in an exercise in water program on a regular basis can be considered as an effective and reliable method to decrease pain, promote the operation of knee and the old men life's quality(Khanjari et. al 2015).

When analyzing the time intervals between the evaluations according to the scales, it was observed that there was a greater gain in balance during the first stage of the program (up to the sixth week), as was seen by Simmons and Hansen (1996). These results possibly occurred because the responses to physical exercise are more evident during the first weeks of treatment. In the initial phase, neural changes predominate, and in the intermediate phase muscle adaptations predominate. In elderly people, the muscle strength increases are mainly due to neural adaptations, which occur with greater magnitude during the first six to eight weeks of training (Komi1986;Hakkinen1998).

In the present study, the water cure program by aquatic devices was applied throughout the whole period. It is possible that modifying the program during the treatment, with progressive exercises (increasing intensity, frequency and duration) would allow results of greater magnitude.

Another possible hypothesis which may explain this result relates to the limitations of the scales that were used. This meant that there was no possibility of measuring new abilities in the next period. The Sharpened Romberg test (static balance with eyes open and close) has a increased times and many of the elderly men came very close to this value after the eight weeks; and the Timed Up \& Go test cannot indefinitely show reducing times. As a reference, $10 \mathrm{~s}$ is the time considered normal for healthy and independent elderly people (Podsiadlo\&Richardson1991).Furthermore, other functional tests that were used to evaluate balance, such as functional reach, Tinetti gait and balance scale and the dynamic gait index resulted in similar limitations.

The proposal of this water cure program consisted of stimulating static and dynamic balances reactions, in order to promote increased static balance and velocity of gait among elderly men. It also sought to create a program that would be easy to replicate, since each exercise and its frequency, intensity and duration were described, differently from most studies on this same theme, in which the descriptions of the programs are simple and general (Booth2004; Simmons\&Hansen1996; Lord et al 1993,Douris et al 2003;Devereux et al 2005; Resende et al 2008). Well defined programs are fundamental for reproducing new research, and for confirmation of the results. Given the benefits of hydrotherapy including easy training, cost effectiveness, no need for special equipment, and the results of the current study, it is suggested that the authorities seize the opportunity to improve the physical health condition, and consequently improve the quality of life for the elderly people by providing proper facilities and exercise environments, particularly, hydrotherapy clinics specifically designated for performing easy and exhilarating exercise for the senile people.

\section{Reference}

[1] Khanjari Y, et al(2015). The effect of a period of aquatic therapy exercise on the quality of life and depression in aged males suffering from chronic physical pains. International congress on behavioral sciences. 14 May 2015.Tehran.Iran.

[2] Khanjari Y, Garooei R(2015). The effect of a period of physical exercise in water on the knee osteoarthritis in old men. International Letters of Natural Sciences Vol. 44 ,pp 64-71, Switzerland. http://dx.doi.org/10.18052/www.scipress.com/ILNS.44.64

[3] Barnett A, Smith B, Lord SR, Williams M, Baumand A. (2003). Community-based group exercises improves balance and reduces falls in at-risk older people: a randomised controlled trial. Age Aging.32:407-14.

[4] 2. Booth CE. (2004). Water exercise and its effects on balance and gait to reduce the risk of falling in older adults. Activities, Adaptation Aging.28(4):45-57. 
[5] Caromano FA, Candeloro JM.( 2007). Fundamentos da hidroterapia para idosos. .5(2):187 95.

[6] Carter ND, Kannus P, Khan KM(2001). Exercise in the prevention of falls in older people: a systematic literature review examining the rationale and the evidence. Sports Med.31(6):42738.

[7] Devereux K, Roberston D, Briffa NK.( 2005). Effects of a water-based program on women 65 years and over: a randomized controlled trial. Aust J Physiother.51(2):102-8.

[8] Douris P, Southard V, Varga C, Schauss W, Gennaro C, Reiss A.(2003). The effect of land and aquatic exercise on balance score in older adults. J Geriatr Phys Ther. 26(1):3-6.

[9] Fuller GF.( 2000). Falls in the elderly. Am Family Fhysician.61:2159-68.

[10] Geigle PR, Cheek WL, Gould ML, Hunt HC, Shafiq B.( 1997). Aquatic physical therapy for balance: the interaction of somatosensory and hydrodynamic principles. The Journal of Aquatic Physical Therapy.5(1):4-10.

[11] Gregg EW, Pereira MA, Caspersen CJ. (2000). Physical activity, falls, and fractures among older adults: A review of the epidemiologic evidence. J Am Geriatr Soc.48:883-93.

[12] Hakkinen K, Kallinen M, Izquierdo M, Jokelainen K, Lassila H, Malkia E, et al. (1998). Changes in agonist-antagonist EMG, muscle CSA, and force during strength training in middle-aged and older people. J Appl Physiol. 84:1341-9.

[13] Hakkinen K, Kallinen M, Izquierdo M, Jokelainen K, Lassila H, Malkia E, et al. (1998). Changes in agonist-antagonist EMG, muscle CSA, and force during strength training in middle-aged and older people. J Appl Physiol. 84:1341-9.

[14] Komi PV. (1986). Training of muscle strength and power: interaction of neuromotoric, hypertrophic, and mechanical factors. Int J Sports Med.7:10-5.

[15] Lord S, Mitchell D, Willians P. (1993). Effect of water exercise on balance and related factors in older people. Aust Physio.39(3):217-22.

[16] Lord SR, Matters B, George RS.( 2006). The effects of water exercise on physical functioning on older people. Aust J Ageing.25(1):36-41.

[17] Miyamoto ST, Lombardi Junior I, Berg KO, Ramos LR, Natour J.( 2004). Brazilian version of the Berg balance scale. Braz J Med Biol Res.37:1411-21.

[18] Newton RA.( 1995). Standing balance abilities of elderly subjects under altered visual and support surfaces. Phys Can.;47:25-9.

[19] Paula K, Yim-Chiplis Laura AT.( 2000). Defining and measuring balance in adults. Biol Res Nurs, 1: 321-331.

[20] Resende SM, Rassi CM, Viana FP (2008). Effects of hydrotherapy in balance and prevention of falls among elderly women. Rev Bras Fisioter.12(1):57-63

[21] Rissel C. (1987).Water exercises for the frail elderly: a pilot programme. Aust J Physiother. 33(4): 226-32.

[22] Salzman, AP. (1998).Evidence-based aquatic therapy for proprioceptive-training. The Aquatic Resources Network. Set H95-9.

[23] Shumway-Cook A, Baldwin M, Polissar NL, Gruber W. (1997).Predicting the probability for falls in community-dwelling older adults. Phys Ther.77(8):812-9.

[24] Simmons V, Hansen PD.(1996). Effectiveness of water exercise on postural mobility in the well elderly: an experimental study on balance enhancement. J Gerontol.51A(5):M233-8.

[25] Stevens JA, Olson S.( 2000). Reducing falls and resulting hip fractures among older women. MMWR Morb Mortal Wkly Rep. 49:1-12 